DOI 10. 18307/2019. 0613

(C) 2019 by Journal of Lake Sciences

\title{
表面流湿地沉积物再悬浮及其对湿地净化效果的影响”
}

\author{
秦文凯 ${ }^{1}$, 李一平 ${ }^{1 * *}$, 杜观超 ${ }^{2}$, 陈红卫 ${ }^{3}$, 高 㝵 $^{2}$, 李峰东 ${ }^{2}$, 朱立琴 ${ }^{4}$ \\ ( 1 : 河海大学环境学院,南京 210098$)$ \\ (2:盐城市盐龙湖饮用水源管理处,盐城 224014) \\ (3:盐城市节约用水办公室,盐城 224001) \\ (4:河海大学马克思主义学院,南京 210098)
}

\begin{abstract}
摘 要: 选取典型表面流人工湿地一一盐龙湖人工湿地为研究对象, 通过对沉积物理化性质分析, 湿地系统水动力模拟, 风场与悬浮物 (SS) 再悬浮浓度关系的拟合及全年再悬浮对湿地净化效果的影响估算, 探索表面流湿地沉积物在动力条 件下的再悬浮特征及此过程中营养物质的再悬浮量. 结果显示: $0.3 \sim 0.5 \mathrm{~m}$ 水深沉积物的理论起动流速在 $18.54 \sim 22.62$ $\mathrm{cm} / \mathrm{s}$ 之间, 模拟得到湿地运行过程中水体流速最大值为 $1.62 \mathrm{~cm} / \mathrm{s}$, 会远小于理论起动流速值, 因此湿地内部流动产生的 底部扰动难以形成湿地底泥的大规模再悬浮现象. 但湿地内部仍存在一定的底泥再悬浮效应, 风场扰动是主要影响因 素, 风场作用受植物影响显著, 萌发期 (3-4 月) 和收割期 (11 月一次年 2 月) 再悬浮贡献量大于生长期 (5-8 月) 与成熟 期 ( $9-10$ 月), 并且当风速 $>4 \mathrm{~m} / \mathrm{s}$ 时再悬浮浓度明显增加. 再悬浮浓度与运行水深也有关, $0.3 \mathrm{~m}$ 水深 SS 再悬浮浓度分 别高出 $0.4 \mathrm{~m}$ 和 $0.5 \mathrm{~m}$ 水深 $12.48 \%$ 和 $18.67 \%$; 高镇酸盐指数 $\left(\mathrm{COD}_{\mathrm{Mn}}\right.$ ) 分别高出 $12.61 \%$ 和 $19.52 \%$; 总氮 $(\mathrm{TN})$ 分别高出 $248.12 \%$ 和 $341.94 \%$; 总磷 ( TP ) 分别高出 $35.53 \%$ 和 $43.48 \%$. 全年 $\mathrm{SS} 、 \mathrm{COD}_{\mathrm{Mn}}$ 、 TN 和 TP 再悬浮量分别达到 $2.8 、 0.47 、 0.15$ 和 $0.011 \mathrm{~kg} / \mathrm{m}^{2}$.
\end{abstract}

关键词: 人工湿地;沉积物再悬浮;起动流速;扰动; 营养物质释放; 盐龙湖

\section{The effect of surface sediment resuspension on constructed wetland purification}

\author{
QIN Wenkai $^{1}$, LI Yiping ${ }^{1 * *}$, DU Guanchao ${ }^{2}$, CHEN Hongwei ${ }^{3}$, GAO Xu ${ }^{2}$, LI Fengdong $^{2} \&$ ZHU Liqin $^{4}$ \\ (1: College of Environment, Hohai University, Nanjing 210098, P.R.China) \\ (2: Yancheng Yanlong Lake Drinking Water Source Management Office, Yancheng 224014, P.R.China) \\ (3: Yancheng City Water Conservation Office, Yancheng 224001, P.R. China) \\ (4: School of Marxism, Hohai University, Nanjing 210098, P.R. China)
}

\begin{abstract}
This paper chose the typical surface flow constructed wetland of Lake Yanlong as study site. Through analysis of sedimentary physical properties, the hydrodynamic simulation of wetland system, the relationship between wind and resuspension, the estimation of resuspension of sediments throughout the year, this paper explored the resuspension characteristics of surface wetland sediments under dynamic conditions and the amount of nutrients resuspended in the process. Results show that the incipient velocity is between 18.54 and $22.62 \mathrm{~cm} / \mathrm{s}$ within the depth of $0.3-0.5 \mathrm{~m}$, but the maximum flow rate of water in and out of the actual wetland operation is $1.62 \mathrm{~cm} / \mathrm{s}$. It is much smaller than the incipient velocity. Therefore, the bottom disturbance caused by the internal flow of the wetland is difficult to form a large-scale resuspension. However, there is still a sediment resuspension effect inside the wetland. Wind field are the main influencing factors, while the wind is significantly affected by plants. The resuspension contribution during the plant germination period (Mar.-Apr.) and harvesting period (Nov. to the next Feb.) is significantly greater than the growth period (May-Aug.) and maturity period (Sep.-Oct.). When the wind speed is $>4 \mathrm{~m} / \mathrm{s}$, the amount of resuspension ( AR) increases obviously. The AR is also related to the water depth. The AR of $0.3 \mathrm{~m}$ water depth is higher than the AR of $0.4 \mathrm{~m}$
\end{abstract}

* 国家重点基础研发计划(2017YFC0405203)、国家自然科学基金项目 (51879082) 和中央高校基本科研业务费专项 资金 (2018B48214,2017B20514) 联合资助. 2018-11-06 收稿; 2019-04-27 收修改稿. 秦文凯 (1994 ), 男, 硕士 研究生;E-mail: 1538850786@ qq.com.

** 通信作者;E-mail: liyiping@ hhu.edu.cn. 
and $0.5 \mathrm{~m}$ with $12.48 \%$ and $18.67 \%$, respectively; chemical oxygen demand $\left(\mathrm{COD}_{\mathrm{Mn}}\right)$ is higher than $12.61 \%$ and $19.52 \%$; total nitrogen ( TN) is higher than $248.12 \%$ and $341.94 \%$; total phosphorus ( TP) is higher than $35.53 \%$ and $43.48 \%$. The annual nutrient resuspension contribution was $2.8 \mathrm{~kg} / \mathrm{m}^{2}$ for $\mathrm{SS}, \sim 0.47 \mathrm{~kg} / \mathrm{m}^{2}$ for $\mathrm{COD}_{\mathrm{Mn}}, \sim 0.15 \mathrm{~kg} / \mathrm{m}^{2}$ for TN, and $\sim 0.011 \mathrm{~kg} / \mathrm{m}^{2}$ for TP.

Keywords: Constructed wetland; sediment resuspension; incipient velocity; disturbance; nutrient release; Yanlong Lake

湿地作为一种生态处理技术, 近年来已得到越来越广泛的应用,但对于表面流湿地来说, 由于其运行水 深浅、占地面积大, 使得沉积物受扰动作用显著, 富集在沉积物中的营养物质极易被再次释放进人上覆水 体 $^{[1-4]}$, 是形成湿地内源污染不可忽视的一部分, 因此, 明晰湿地沉积物的再悬浮过程及其对净化效果的影 响非常关键. Wilson 等 ${ }^{[5]}$ 以水体中悬浮固体的 ${ }^{7} \mathrm{Be}^{210} \mathrm{~Pb}_{\mathrm{xs}}$ 表征了 Old Woman Creek 滨海天然湿地短期内总悬 浮固体沉积与再悬浮的动态过程,估算单次径流事件中悬浮物的净输出量. Ganju 等 ${ }^{[6]}$ 分析了潮汐湿地不同 时期水量、风及气压等影响因素作用下再悬浮量的差异. Marion 等 ${ }^{[7]}$ 研究表明湿地环境会促使部分营养物 质由颗粒态转化为溶解态, 再悬浮可引起水体的富营养化及河口的淤塞. Gargallo 等 ${ }^{[8-9]}$ 在表面流人工湿地 悬浮物敏感参数分析中发现与风相关的参数对再悬浮过程影响显著. 除此之外, 人为扰动、底栖生物的扰 动、强降雨等都会产生一定程度的影响, 其中人为扰动、短期的强降雨等会形成短期内的强烈释放现象, 但 并不会对全年趋势的研究产生明显影响, 底栖生物的扰动受季节影响明显, 流场和风场的变化是长周期研 究中沉积物再悬浮的主要影响因素. 相关研究大多是关于开阔水域再悬浮过程及营养盐响应特征的分 析 ${ }^{[10-12]}$, 对于植物种植区的研究也大多是研究动力条件影响下悬浮沉降的变化规律 ${ }^{[13]}$, 对于定量分析再悬 浮过程中营养盐释放特征的研究较少.

盐龙湖人工湿地作为国内少有的大型表面流人工湿地,整体生态工程主要由预处理区、挺水植物区、沉 水植物区及深度净化区 4 部分构成, 自建成以来已稳定运行 6 年之久, 但由于挺水植物区水力负荷高、停留 时间短, 使得植物对水体营养物质的吸收能力有限, 湿地土壤表面的截留、吸附作用是挺水植物区水质净化 的关键, 沉积物再悬浮会显著影响湿地的净化效果, 因此, 盐龙湖湿地挺水植物区可作为理想的湿地沉积物 再悬浮及其对湿地净化效果影响的研究区域. 本文基于分析湿地内部不同环境再悬浮与流场、风场的长期 动态响应过程, 估算再悬浮及其对湿地净化效果影响, 以期为今后表面流湿地再悬浮污染控制研究提供 参考.

\section{1 仪器与方法}

\section{1 研究区域概况}

盐龙湖人工湿地位于江苏省盐城市龙冈镇境内, 占地面积约 220 万 $\mathrm{m}^{2}$, 是集净化、调蓄与稳定功能于一 体的饮用水生态处理工程. 其中表面流湿地挺水植 物区作为水质净化的核心单元之一, 总面积 40 万 $\mathrm{m}^{2}$, 以原位土壤为基质, 以芦苇、萃草为优势物种, 植 物密度 70 100 株/ $\mathrm{m}^{2}$, 进水被分为东西相同的两侧, 每侧沿水流方向分为 3 部分, 正常运行水深依次为 $0.3 、 0.4$ 和 $0.5 \mathrm{~m}$, 每部分又被分为 3 组并联运行且相 互独立,水流沿进水渠进入湿地,经两侧出水渠收集 后由出水堰流出,整体水力停留时间约 $12 \mathrm{~h}$,处理水 量 30 万 35 万 $\mathrm{t} / \mathrm{d}$. 研究区域内 $2016-2017$ 年平均 进、出水水质见表 1 .

表 12016 - 2017 年盐龙湖平均进、出水水质

Tab.1 Average influent and effluent water quality in Yanlong Lake from 2016 to 2017

\begin{tabular}{cccc}
\hline 检测指标 & 进水水质 & 出水水质 & 去除率/\% \\
\hline 浊度 $/ \mathrm{NTU}$ & 29.84 & 27.09 & 9.22 \\
$\mathrm{COD}_{\mathrm{Mn}} /(\mathrm{mg} / \mathrm{L})$ & 6.03 & 6.08 & -0.83 \\
$\mathrm{NH}_{3}-\mathrm{N} /(\mathrm{mg} / \mathrm{L})$ & 0.45 & 0.36 & 20.00 \\
$\mathrm{TN} /(\mathrm{mg} / \mathrm{L})$ & 1.77 & 1.54 & 12.99 \\
$\mathrm{TP} /(\mathrm{mg} / \mathrm{L})$ & 0.19 & 0.18 & 5.26 \\
\hline
\end{tabular}

\section{2 样品采集}

本研究于 2017 年 12 月采用重力柱状采样器分别在西侧 $0.3 、 0.4$ 和 $0.5 \mathrm{~m}$ 水深区域采集沉积物柱状样, 每个区域分别在进水口、中间、出水口位置取样, 将柱状样现场进行分割, 表层 $0 \sim 4 \mathrm{~cm}$ 按 $1 \mathrm{~cm}$ 间隔分割, 其 余部分沿纵向每 $10 \mathrm{~cm}$ 分割 1 次, $30 \mathrm{~cm}$ 以下沉积物弃去, 将处理好的样品密封、标记, 在 $4^{\circ} \mathrm{C}$ 下冷藏用于沉 
积物理化性质分析; 于 2016 年 3 月至 2017 年 2 月每天采集进水渠及出水渠水样, 同时收集风力气象数据, 取每天最大平均时风速为研究对象, 用于再悬浮量与风场相关性分析; 于 2018 年 4 月采集研究区域内不同 位置水样共 30 组, 分 3 次进行, 分析得到每个样品的浊度及 SS, 用于浊度与 SS 关系的标定; 同时分别在 $0.3 、 0.4 、 0.5 \mathrm{~m}$ 水深进水口及出水口采集水样, 每 5 天采集 1 次, 共 6 次, 用于水质指标分析. 具体采样点布 置如图 1 所示 ( I, J 为网格坐标点).

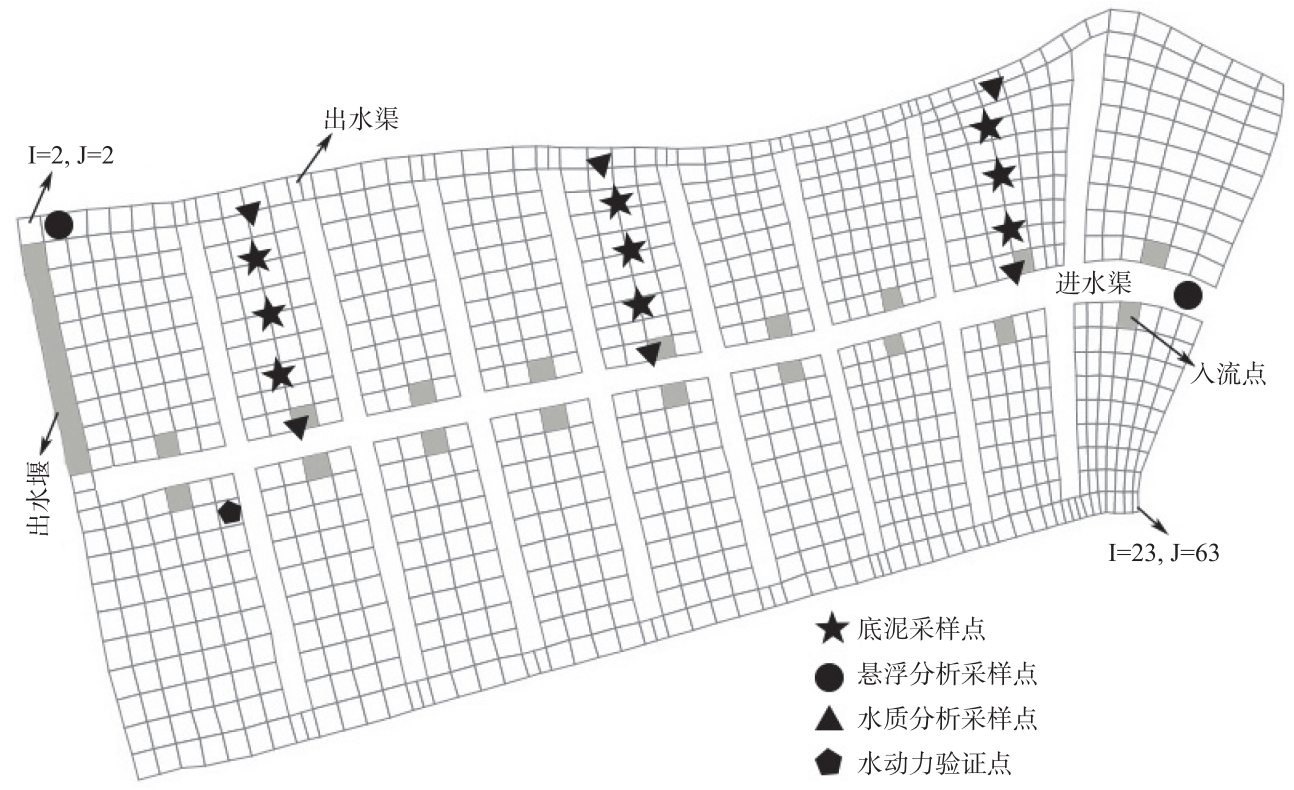

图 1 盐龙湖湿地采样监测点布置及网格划分

Fig.1 Location of sampling sites in Yanlong Lake wetland and grid generation

\section{3 分析方法}

水质浊度采用便携式浊度仪 (HACH 2100Q) 测定, 悬浮物 ( SS) 含量采用重量法测定, 高锰酸盐指数 $\left(\mathrm{COD}_{\mathrm{Mn}}\right)$ 采用酸性高锰酸钾滴定法测定, 氨氮 $\left(\mathrm{NH}_{3}-\mathrm{N}\right)$ 浓度采用纳氏试剂分光光度法测定, 水质总氮 ( TN ) 浓度采用碱性过硫酸钾紫外分光光度法测定, 水质总磷 (TP) 浓度采用钼酸铵分光光度法测定; 沉积物含水 率采用烘干称重法测定, 孔隙率采用环刀法测定, 粒径分布采用马尔文 3000 激光粒径分析仪法测定, 总有 机碳( TOC) 含量采用浓硫酸重铬酸钾氧化外加热法测定, 沉积物 TN 含量采用半微量开氏法测定, 沉积物 TP 含量采用碱融-钼锑抗比色法 ${ }^{[14]}$ 测定.

\section{4 数据处理}

1.4.1 沉积物临界起动流速及临界切应力计算 关于细泥沙颗粒的再悬浮计算, 窦国仁 ${ }^{[15]}$ 通过对床面泥沙 颗粒起动受力情况进行分析, 并结合实践及现场观察, 提出泥沙起动时的三种状态, 张红武 ${ }^{[16]}$ 对现有部分公 式在河床摩阻特性方面进行修正, 以窦国仁早期给出的泥沙起动条件为基础, 建立了更具有普遍性的泥沙 起动流速计算公式:

$$
V=2.1 K_{d}\left[\frac{r_{s}-r}{r} g \cdot d_{50}+6.59 \frac{r_{s}-r}{r} g^{0.33}\left(\frac{r_{0}}{r_{0}^{*}}\right)^{6.6} \frac{\nu^{1.34}}{d_{50}}+0.0352\left(\frac{r_{0}}{r_{0}^{*}}\right)^{6.6} \frac{g \cdot h \cdot \delta}{d_{50}}\right]^{0.5}
$$

式中, $r_{s}$ 为沉积物容重 $\left(\mathrm{kg} / \mathrm{m}^{3}\right) ; r$ 为水的容重 $\left(\mathrm{kg} / \mathrm{m}^{3}\right) ; \delta$ 为薄膜水厚度参数 $(\mathrm{m}) ; d_{50}$ 为中值粒径 $(\mathrm{m}) ; h$ 为水 深 $(\mathrm{m}) ; r_{0}$ 为泥沙干容重 $\left(\mathrm{kg} / \mathrm{m}^{3}\right), r_{0}{ }^{*}$ 为稳定干容重 $\left(\mathrm{kg} / \mathrm{m}^{3}\right), \nu$ 为水的运动学粘滞系数 $\left(\mathrm{m}^{2} / \mathrm{s}\right), K_{d}$ 为平均流 速的换算参数,无量纲, 具体计算公式为:

$$
K_{d}^{-1}=1-\frac{9.42 \sqrt{g}}{8 C \cdot m_{k}}+\frac{\sqrt{g}}{C \cdot m_{k}}\left[\sqrt{\frac{2 d_{50}}{3 h}-\left(\frac{2 d_{50}}{3 h}\right)^{2}}+\arcsin \sqrt{\frac{2 d_{50}}{3 h}}\right]
$$


式中, $C$ 为谢才系数 $\left(\mathrm{m}^{0.5} / \mathrm{s}\right), m_{k}$ 为涡团参数,无量纲,具体计算公式为:

$$
m_{k}=0.15\left[1-4.2 \sqrt{S_{\mathrm{V}}}\left(0.365-S_{\mathrm{V}}\right)\right]
$$

式中, $S_{\mathrm{v}}$ 为体积含沙量 $(\mathrm{mg} / \mathrm{L})$.

在考虑植被阻力作用的基础上, 结合房春艳 ${ }^{[17]}$ 给出的关于植被与曼宁糔率系数之间的关系, 根据曼宁 䊁率系数计算谢才系数, 具体计算公式为:

$$
\begin{aligned}
& n=\frac{R^{2 / 3} \kappa^{1 / 2} Y_{d}^{1 / 2}}{(2 g)^{1 / 2}} \\
& C=\frac{1}{n} \cdot R^{1 / 6}
\end{aligned}
$$

式中, $R$ 为水力半径 $(\mathrm{m}) ; \kappa$ 为植物密度 $\left(\right.$ 株 $\left./ \mathrm{m}^{2}\right) ; Y_{d}$ 为植物拖曳力系数, 无量纲, 其值与雷诺数有关, $n$ 为曼 宁粘率系数, 无量纲, 其中季振刚 ${ }^{[18]}$ 在模拟 Okeechobee 湖时取值为 $0.02 \sim 0.10 \mathrm{~m}$, 窦明等 ${ }^{[19]}$ 在模拟龙风湿地 时取值为 $0.032 \mathrm{~m}$, 本研究中结合湿地实际水动力情况, 率定结果为 $0.04 \mathrm{~m}$.

结合窦国仁 ${ }^{[15]}$ 给出的关于起动流速与临界起动切应力之间的关系式, 以少量动作为起动标准, 推导出 沉积物的临界起动切应力 $(\tau)$ 计算公式为:

$$
\tau=0.0278 r\left(\frac{\Delta}{h}\right)^{2} V^{2}
$$

式中, $\Delta$ 为床面粗粘高度 $(\mathrm{m})$, 其值与中值粒径有关.

1.4.2 水动力模型概况 采用二维水动力模型对盐龙湖 湿地挺水植物区水动力进行模拟. 构建正交曲线网格, 共划分网格 933 个,网格单元最大边长 $28.3 \mathrm{~m}$ (图 1), 垂 向分 1 层,模型使用附近气象站点气象数据及实际进出 湿地流量作为边界条件,模拟起始时间为 2016 年 1 月 1 日,初始水位为湿地工程设计标高 $(2.85 \mathrm{~m})$, 初始流速设 为 $0 \mathrm{~m} / \mathrm{s}$, 水温将模拟第 $1 \mathrm{~d}$ 输人值均匀赋给各空间网格 作为初始值, 时间步长为 $12 \mathrm{~s}$, 计算时间为 $1 \mathrm{a}$, 其余主要 水动力参数见表 2 .

表 2 主要水动力参数

Tab. 2 Important hydrodynamic parameters

\begin{tabular}{lc}
\hline 参数描述 & 数值 \\
\hline 湿地底部粗鋉高度 $/ \mathrm{m}$ & 0.04 \\
网格切换为“干”的水深 $/ \mathrm{m}$ & 0.11 \\
网格切换为 “湿” 的水深 $/ \mathrm{m}$ & 0.16 \\
涡流粘度 $/\left(\mathrm{m}^{2} \cdot \mathrm{s}\right)$ & $1 \times 10^{-6}$ \\
太阳辐射调整系数 & 0.8 \\
\hline
\end{tabular}

水位、流速和水温验证结果显示, 水位模拟结果全年均值为 $2.843 \mathrm{~m}$,与湿地全年平均设计常水位 2.85 $\mathrm{m}$ 基本吻合, 流速模拟值与实测值相对均方根误差 $(R R E)$ 值为 $2.94 \%$, 水温模拟结果与实测结果 (实测水温 点与悬浮分析采样点位置相同) 的 $R R E$ 值为 $5.30 \%$, 较为准确地模拟了湿地水动力的变化过程, 模型可用于 湿地的水动力情况分析.
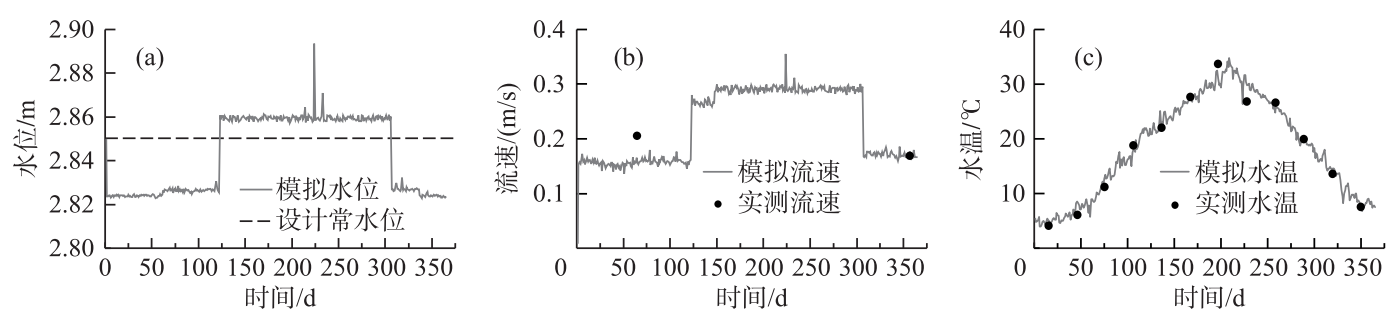

图 2 水位 $(a)$ 、流速 $(b)$ 和水温 $(c)$ 验证结果

Fig.2 Validation results of water level (a), velocity (b) and water temperature (c)

1.4.3 静置浓度变化量与再悬浮浓度的测定方法 实验在 $\varnothing 90 \mathrm{~mm} \times 80 \mathrm{~cm}$ 有机玻璃管中进行, 有机玻璃管下 端用橡胶塞密封, 实验时在进水渠采集原水, 将采集水样摇匀后加人有机玻璃管中, 水深分别为 $0.3 、 0.4$ 和 $0.5 \mathrm{~m}$, 加水后立即使用虹吸法采集液面以下中间位置处水样 $50 \mathrm{ml}$ 用于水质浊度检测, 模拟湿地理论水力 停留时间, $0.3 \mathrm{~m}$ 水深静置 $175 \mathrm{~min}, 0.4 \mathrm{~m}$ 水深静置 $230 \mathrm{~min}, 0.5 \mathrm{~m}$ 水深静置 $290 \mathrm{~min}$ 后再次采样检测, 静置 
过程中不同水深特定时间内 $\mathrm{SS}$ 的浓度变化定义为 $\mathrm{SS}$ 的静置浓度变化量 $\left(C_{\mathrm{SS}}\right)$, 不同水深设置 3 组对照实 验, 不同进水时间段采集原水水样共 5 次, 用于拟合原水 $\mathrm{SS}$ 与 $C_{\mathrm{ss}}$ 之间的关系曲线,进一步根据全年水质 $\mathrm{SS}$ 监测数据反演对应 $C_{\mathrm{ss}}$. 由进、出水 $\mathrm{SS}$ 差值来表示湿地 $\mathrm{SS}$ 的综合浓度变化量 $\left(Q_{\mathrm{sS}}\right)$ (公式 $(7)$ ), 再悬浮浓度 根据静置浓度变化量与综合浓度变化量差值计算 (公式 (8)). 实验期间, 室温保持在 $25^{\circ} \mathrm{C}$.

$$
\begin{gathered}
Q_{\mathrm{ss}}=C_{0}-C_{1} \\
Z_{\mathrm{SS}}=C_{\mathrm{sS}}-Q_{\mathrm{ss}}
\end{gathered}
$$

式中, $Z_{\mathrm{sS}}$ 为再悬浮浓度 $(\mathrm{mg} / \mathrm{L}), C_{0}$ 为进水 $\mathrm{SS}$ 浓度 $(\mathrm{mg} / \mathrm{L}), C_{1}$ 为出水 $\mathrm{SS}$ 浓度 $(\mathrm{mg} / \mathrm{L})$.

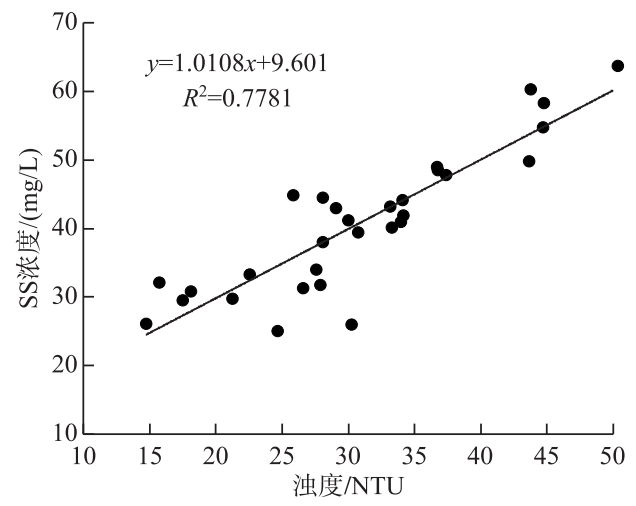

图 3 浊度与 SS 浓度相关性标定

Fig. 3 Calibration of correlation between turbidity and SS concentration

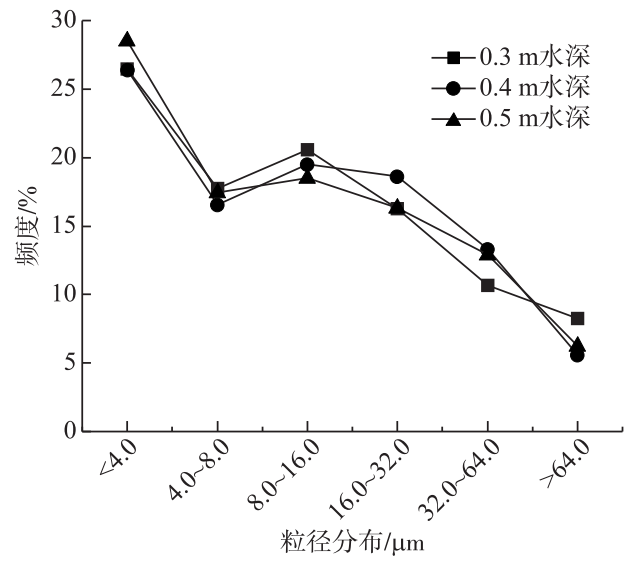

图 4 不同水深沉积物粒径分布

Fig.4 Particle size distribution of sediments at different water depths

1.4.4 水质浊度与悬浮物浓度的关系标定 浊度与 SS 浓 度之间的相关性拟合曲线如图 3 , 通过将浊度序列转换为 $\mathrm{SS}$ 序列, 分析发现两者之间的相关性良好 $\left(R^{2}=0.78\right)$, 可 用于 SS 浓度的推演及风速与 SS 浓度之间的定量分析.

\section{2 结果与分析}

\section{1 沉积物理化性质特征}

从沉积物粒径 ( 图 4) 来看, 不同水深粒径分布差别 不大, 大部分沉积物粒径介于 $0 \sim 64.0 \mu \mathrm{m}$ 之间, 这部分颗 粒占到 $91.7 \% \sim 94.4 \%$, 其中小于 $4 \mu \mathrm{m}$ 颗粒比例占到 $24.0 \% \sim 31.0 \%$, 在巢湖湿地 ${ }^{[20]}$ 研究中得到与此相似的分 布规律,但巢湖湿地中不同深度中值粒径最小值为 14.2 $\mu \mathrm{m}$, 总的来说, 盐龙湖湿地沉积物颗粒粒径更小.

从沉积物中值粒径(图 5a)、含水率(图 $5 b$ ) 的纵向分 布来看, $0 \sim 10 \mathrm{~cm}$ 中值粒径呈现出随深度先减小后增加 的趋势, 含水率的变化恰好相反, 表现为先上升后下降, 不同水深沉积物的中值粒径均值介于 $8.48 \sim 9.5 \mu \mathrm{m}$ 之 间,含水率在 $53.19 \% \sim 74.4 \%$ 之间, $10 \mathrm{~cm}$ 以下粒径、含水 率分别稳定在 15.2 20.0 $\mu \mathrm{m}$ 和 23\% 35.19\% 之间. 不同 水深沉积物孔隙率 (c) 随深度整体呈现出略微增加后下 降的趋势, 不同水深之间差别不明显, $0 \sim 10 \mathrm{~cm}$ 孔隙率在 $52.85 \%$ 74. $16 \%$ 之间, $20 \mathrm{~cm}$ 以下孔隙率稳定在 39.69\% $41.45 \%$ 之间.

从沉积物 TN(图 5d)、TP(图 5e)、TOC( 图 5f) 含量随 深度的变化来看, 不同水深 $0 \sim 10 \mathrm{~cm}$ TN 含量总体表现出 先增加后下降的趋势, $3 \sim 4 \mathrm{~cm}$ 处达到最大值, 均值为 $2852.50 \mathrm{mg} / \mathrm{kg}, 0 \sim 1 \mathrm{~cm}$ 为表层 $4 \mathrm{~cm}$ 内最小值, 均值为 $2440.59 \mathrm{mg} / \mathrm{kg}, 4 \sim 10 \mathrm{~cm}$ TN 含量明显下降, $0.3 、 0.4$ 和 0.5 $\mathrm{m}$ 水深分别下降了 $66.49 \% 、 62.58 \%$ 和 $16.25 \%$, 相同水深 $10 \mathrm{~cm}$ 以下 $\mathrm{TN}$ 含量变幅较小, 平均幅度为 $16.60 \%$. 不同 水深 0 4 cm TP 含量介于 $416.38 \sim 648.52 \mathrm{mg} / \mathrm{kg}$ 之间, 4 $10 \mathrm{~cm}$ 之间 TP 含量分别下降了 $51.60 \% 、 41.39 \%$ 和 $33.45 \%$, 相同水深 $10 \mathrm{~cm}$ 以下 TP 含量平均变幅仅为 $6 \%$. 不同水深 $0 \sim 10 \mathrm{~cm}$ TOC 含量趋势与 TN 含量基本一致, 除 $0.4 \mathrm{~m}$ 水深最大值出现在 $1 \sim 2 \mathrm{~cm}, 0.3 \mathrm{~m}$ 与 $0.5 \mathrm{~m}$ 水深最大值均在 3 4 $\mathrm{cm}$ 处, 表层 $0 \sim 4 \mathrm{~cm}$ 范围内 $0 \sim 1 \mathrm{~cm}$ TOC 含量最小, 均值为 $1.89 \%, 3 \sim 4 \mathrm{~cm}$ 处最大, 均 值为 $2.12 \%, 4 \sim 10 \mathrm{~cm}$ 之间 TOC 含量分别下降了 $82.67 \%$ 、 $75.24 \%$ 和 $42.04 \%$. 同时由于 $0.5 \mathrm{~m}$ 水深水力负荷 较 $0.3 \mathrm{~m}$ 水深与 $0.4 \mathrm{~m}$ 水深大, TN 、TP 及 TOC 积累量都相对更高. 

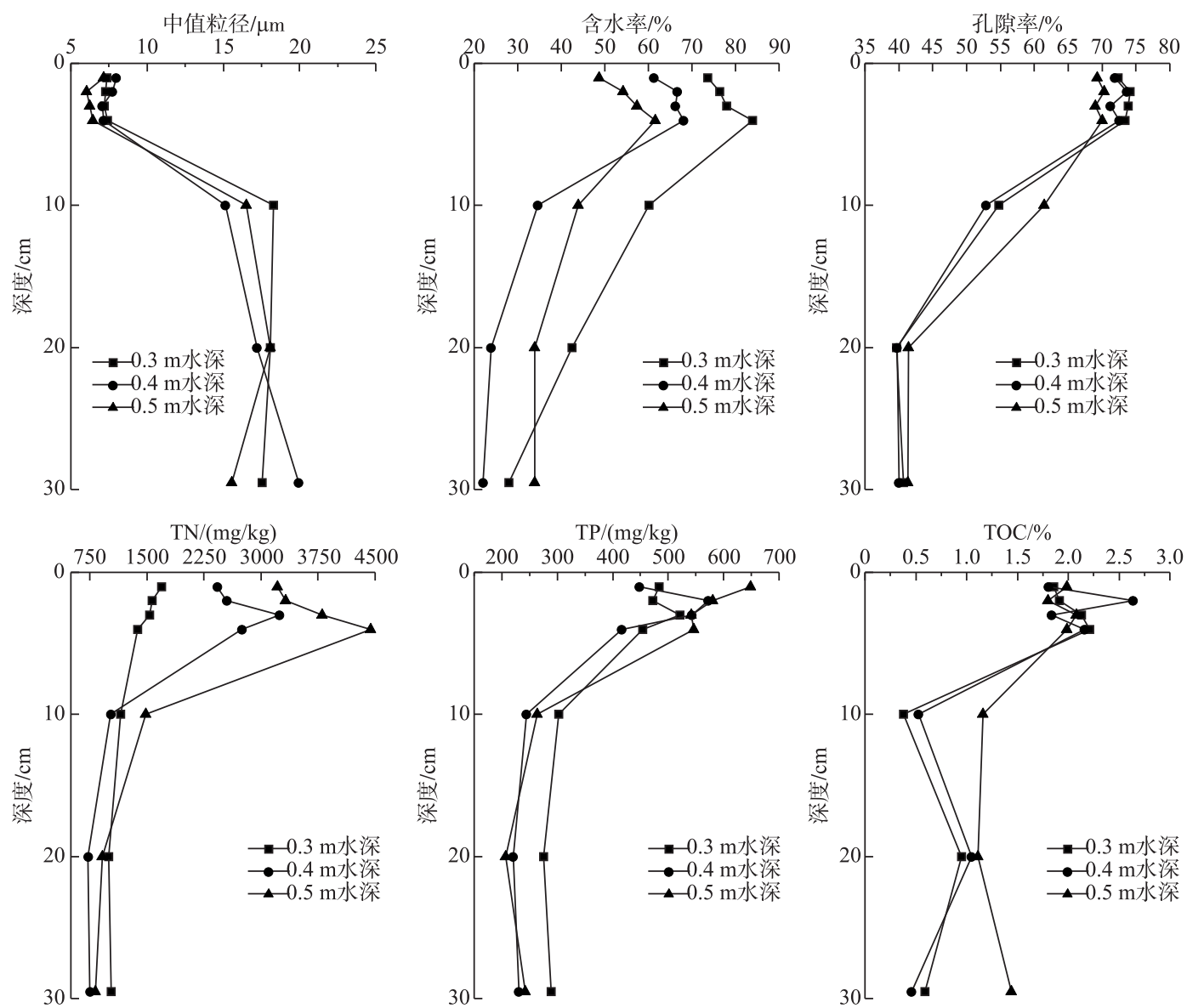

图 5 沉积物中值粒径 $(\mathrm{a})$ 、含水率 $(\mathrm{b})$ 、孔隙率 $(\mathrm{c}) 、 \mathrm{TN}(\mathrm{d}) 、 \mathrm{TP}(\mathrm{e}) 、 \mathrm{TOC}(\mathrm{f})$ 随水深的变化

Fig.5 Sediment medium diameter (a), water content (b), porosity (c), $\mathrm{TN}(\mathrm{d}), \mathrm{TP}(\mathrm{e}), \mathrm{TOC}(\mathrm{f})$ as a function of water depth

\section{2 流场作用下沉积物再悬浮效应}

2.2.1 沉积物起动流速及临界切应力 以垂线平均流速作为 起动流速,其余相关计算参数见表 3 ,各物理要素均采用表 层 $0 \sim 1 \mathrm{~cm}$ 沉积物值, 将表 3 中相关参数代人公式 (1) (6), 得到沉积物起动流速及临界起动切应力 (表 4 ), 结果显 示不同水深起动流速 $(v)$ 介于 $18.54 \sim 22.62 \mathrm{~cm} / \mathrm{s}$ 之间, 临界 切应力 $(\tau)$ 为 $0.0057 \sim 0.0107 \mathrm{~N} / \mathrm{m}^{2}$.

2.2.2 湿地挺水植物区运行流速 根据模型模拟结果, 分别 输出不同水深流速值,得到不同水深的时间与流速曲线图

(图 6), 结果显示全年 $0.3 \mathrm{~m}$ 水深流速介于 $0.90 \sim 1.62 \mathrm{~cm} / \mathrm{s}$ 之间, $0.4 \mathrm{~m}$ 水深流速介于 $0.37 \sim 1.03 \mathrm{~cm} / \mathrm{s}$ 之间, $0.5 \mathrm{~m}$ 水深流速介于 $0.22 \sim 0.95 \mathrm{~cm} / \mathrm{s}$ 之间. 与沉积物的理论再悬浮起动流速相比, 此值远小于理论起动流 速,因此仅湿地内部的流体流动不足以引起沉积物的再悬浮.

\section{3 风场条件下沉积物再悬浮效应}

2.3.1 不同水深静置浓度变化量与进水 SS 之间的关系 通过不同水深的静沉降实验, 结果表明 (图 7): 当进 水 $\mathrm{SS}<35 \mathrm{mg} / \mathrm{L}$ 时, 不同水深之间静置浓度变化量差别较小, 当进水 $\mathrm{SS}>35 \mathrm{mg} / \mathrm{L}$ 时, $0.3 \mathrm{~m}$ 水深明显小于 0.4
Tab.3 Incipient velocity related parameters

\begin{tabular}{cc}
\hline 参数 & 取值 \\
\hline$\delta$ & $2.31 \times 10^{-7} \mathrm{~m}$ \\
$r_{0} / r_{0}^{*}$ & 1 \\
$\nu$ & $1.0299 \times 10^{-3} \mathrm{~m}^{2} / \mathrm{s}$ \\
$S_{\mathrm{V}}$ & $35.56 \mathrm{mg} / \mathrm{L}$ \\
$\kappa$ & 77 株 $/ \mathrm{m}^{2}$
\end{tabular}


表 4 不同水深起动流速及临界起动切应力

Tab.4 Incipient velocity and critical shear stress at different water depths

\begin{tabular}{llrc}
\hline 水深 & $K_{d}$ & $v /(\mathrm{cm} / \mathrm{s})$ & $\tau /\left(\mathrm{N} / \mathrm{m}^{2}\right)$ \\
\hline $0.3 \mathrm{~m}$ & 1.02 & 18.54 & 0.0107 \\
$0.4 \mathrm{~m}$ & 1.02 & 20.65 & 0.0074 \\
$0.5 \mathrm{~m}$ & 1.03 & 22.62 & 0.0057 \\
\hline
\end{tabular}

$\mathrm{m}$ 水深和 $0.5 \mathrm{~m}$ 水深,但 $0.4 、 0.5 \mathrm{~m}$ 水深之间没有表现出显 著性差异. 将不同水深静置浓度变化量与进水 SS 浓度之间 进行曲线拟合, 发现两者之间呈现出较好的二次曲线关系 (表 5).

2.3.2 风场条件下 SS 再悬浮浓度的定量分析 湿地环境中 按植物的生长特点, 可将全年分为 4 个阶段: 萌发期 (3-4 月）、生长期 $(5-8$ 月)、成熟期 ( $9-10$ 月) 和收割期 ( 11 -次 年 2 月). 根据实测进水 SS 浓度, 利用静置浓度变化量与进 水 SS 浓度关系曲线, 得到静置浓度变化量均值, 根据公式 (7) (8) 计算得到沉积物的再悬浮浓度 (图 8). 各个阶段植物的显著差异使得风场的作用也表现出很大不同,结果显示萌发期(图 8a) 当风速 $<2 \mathrm{~m} / \mathrm{s}$ 时, SS 再悬浮浓度均值为 $9.38 \mathrm{mg} / \mathrm{L}$, 风速在 $2 \sim 4 \mathrm{~m} / \mathrm{s}$ 之间时, 为 $17.93 \mathrm{mg} / \mathrm{L}$, 风速 $>4 \mathrm{~m} / \mathrm{s}$ 时, 为 $22.28 \mathrm{mg} / \mathrm{L}$; 生长 期 (图 $8 \mathrm{~b}$ ) 除风速 $>4 \mathrm{~m} / \mathrm{s}$ 时, $\mathrm{SS}$ 再悬浮浓度略微偏高, 达到 $15.68 \mathrm{mg} / \mathrm{L}$, 其余不同风速条件下再悬浮浓度之 间没有显著性差异, 再悬浮浓度介于 10.05 12.96 mg/L 之间; 成熟期 (图 8c) 风速与再悬浮浓度之间也不具 有显著性差异, SS 再悬浮浓度介于 10.26 11.73 mg/L 之间, 10 月 9 日 -10 月 13 日, 水体出水 $\mathrm{SS}$ 浓度出现 较大波动, 再悬浮浓度均值达到 $26.71 \mathrm{mg} / \mathrm{L}$, 明显高于整个阶段的再悬浮浓度, 这可能是局部扰动引起的再 悬浮现象, 在接下来短期 ( 2 天) 内水体的再悬浮浓度又很快与扰动前基本一致; 收割期 (图 $8 \mathrm{~d}$ ) 植物收割造 成的扰动及对土壤结构的破坏较为严重, 使得收割过程 (大约 11-12 月) 及收割过后的约一个月内 SS 再悬 浮浓度都有较为明显的增加, 再悬浮浓度均值为 $16.72 \mathrm{mg} / \mathrm{L}$, 次年 $1-2$ 月风场与再悬浮浓度之间关系与萌 发期类似, 当风速 $<2 \mathrm{~m} / \mathrm{s}$ 时, 再悬浮浓度均值为 $5.86 \mathrm{mg} / \mathrm{L}$, 风速在 $2 \sim 4 \mathrm{~m} / \mathrm{s}$ 之间时, 为 $11.88 \mathrm{mg} / \mathrm{L}$, 风速大 于 $4 \mathrm{~m} / \mathrm{s}$ 时, 达到 $16.35 \mathrm{mg} / \mathrm{L}$.

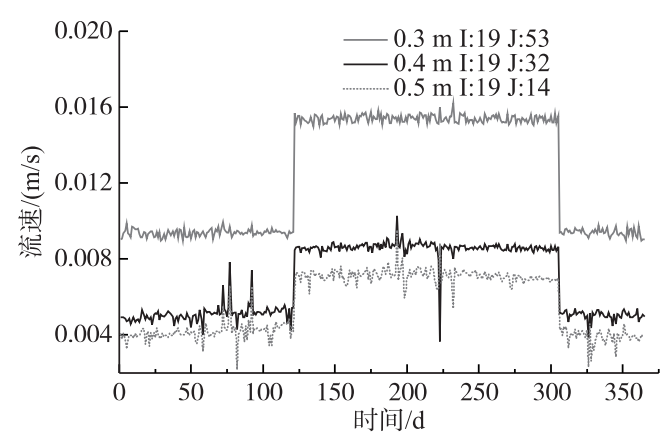

图 6 不同水深流速曲线

Fig.6 Velocity curve at different water depths

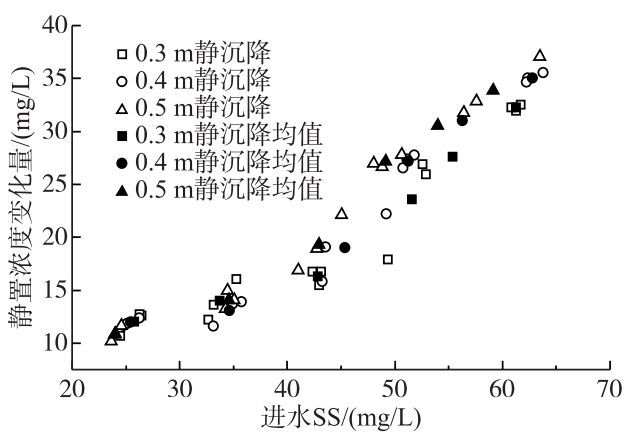

图 7 不同水深静置浓度变化量与进水 SS 浓度的关系

Fig.7 Relationship between static concentration variation of different water depths and influent SS concentration

表 5 不同水深静置浓度变化量 $(y)$ 与进水 SS 浓度 $(x)$ 的关系曲线

Tab.5 Corelation of static concentration variation $(y)$ and influent SS concentration $(x)$ under different water depths

\begin{tabular}{ccc}
\hline 水深 & 拟合曲线函数 & $R^{2}$ \\
\hline $0.3 \mathrm{~m}$ & $y=0.0149 x^{2}-0.7189 x+20.718$ & 0.9930 \\
$0.4 \mathrm{~m}$ & $y=0.0116 x^{2}-0.3463 x+12.496$ & 0.9727 \\
$0.5 \mathrm{~m}$ & $y=0.0105 x^{2}-0.1735 x+8.4381$ & 0.9826 \\
\hline
\end{tabular}

$x 、 y$ 单位均为 $\mathrm{mg} / \mathrm{L}$.

\section{4 再悬浮对湿地净化效果的影响}

水质分析采样时间处于植物萌发期, 此阶段为全年再悬浮量最大阶段, 以此阶段监测数据来估算再悬 浮过程对湿地净化效果影响的最大值. 通过对研究区域整体长期的水质监测结果统计分析得到溶解态 

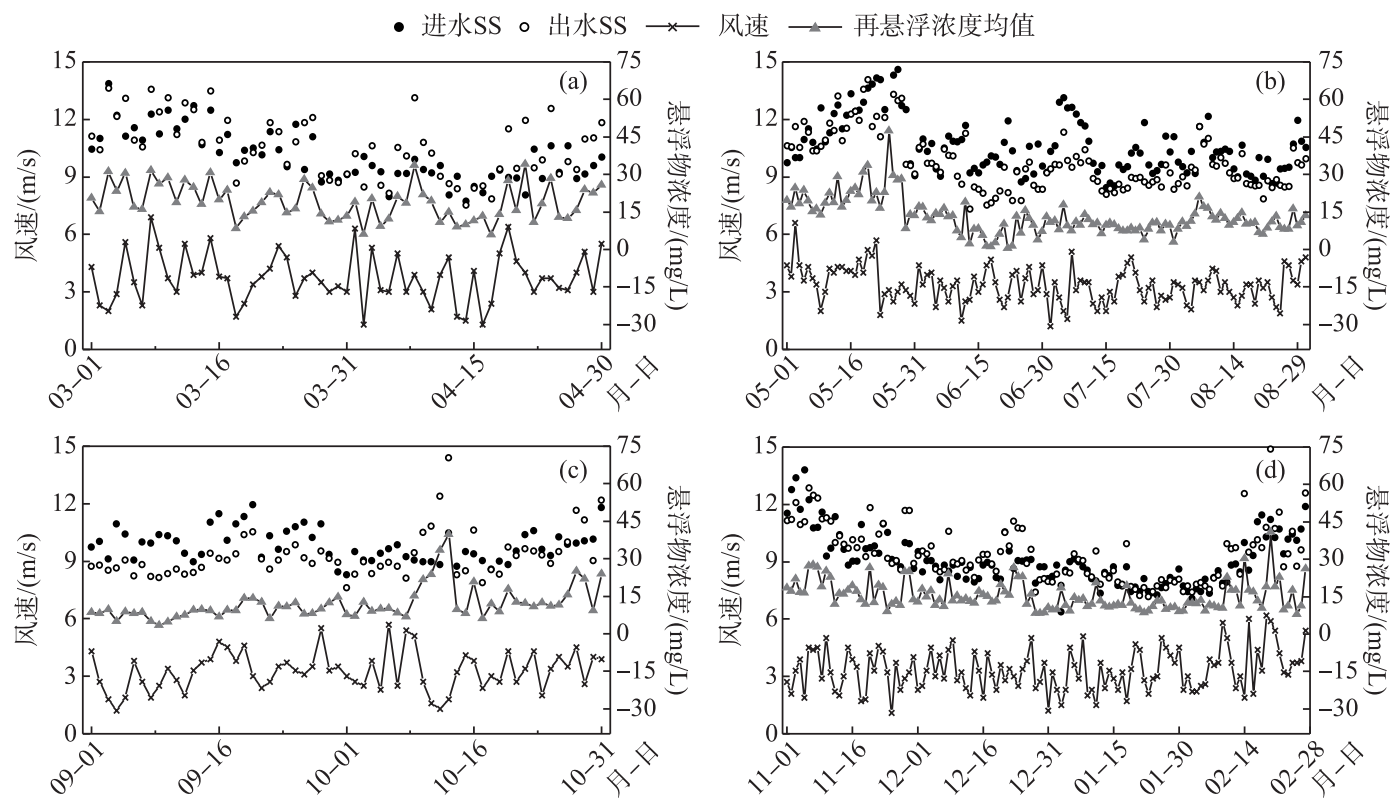

图 8 萌发期 (a)、生长期 (b)、成熟期 (c)、收割期 (d) 风速与 SS 再悬浮浓度关系

Fig.8 Relationship between wind speed and resuspension in germination period (a), growth period (b), maturity (c), harvesting period (d)

$\mathrm{COD}_{\mathrm{Mn}} / \mathrm{COD}_{\mathrm{Mn}}$ 为 0.78 , 总溶解态氮 (TDN) $/ \mathrm{TN}$ 为 0.70 , 总溶解态磷 (TDP) $/ \mathrm{TP}$ 为 0.19 , 因此可根据不同水深 进出水水质 $\mathrm{COD}_{\mathrm{Mn}}$ 、 $\mathrm{TN}$ 及 $\mathrm{TP}$ 实测值计算各对应营养物质颗粒态量, 以往研究中发现 $\mathrm{SS}$ 与颗粒态 $\mathrm{COD}_{\mathrm{Mn}}$ 、 总颗粒态氮 (TPN) 及总颗粒态磷 (TPP) 之间存在明显的正相关性 ${ }^{[21]}$, 对不同水深进出水水质进行分析, 得 到颗粒态 $\mathrm{COD}_{\mathrm{Mn}}$ 、TPN 和 TPP 和 SS 之间的比值关系均值: $0.3 、 0.4$ 和 $0.5 \mathrm{~m}$ 水深 $\mathrm{SS} /$ 颗粒态 $\mathrm{COD}_{\mathrm{Mn}}$ 值分别为 $27.44 、 27.35$ 和 $27.27, \mathrm{SS} / \mathrm{TPN}$ 值分别为 $63.51 、 60.02$ 和 58.31 , SS/TPP 值分别为 $317.86 、 323.04$ 和 329.17. $\mathrm{COD}_{\mathrm{Mn}}$ 、 $\mathrm{TN}$ 及 $\mathrm{TP}$ 的静置浓度变化量以其颗粒态的去除量来表示, 利用 $\mathrm{SS}$ 静置浓度变化量及 $\mathrm{SS} /$ 颗粒态 $\mathrm{COD}_{\mathrm{Mn}} 、 \mathrm{SS} / \mathrm{TPN}$ 和 $\mathrm{SS} / \mathrm{TPP}$ 关系计算 $\mathrm{COD}_{\mathrm{Mn}}$ 、TN 及 $\mathrm{TP}$ 静置浓度变化量, 以静置浓度变化量与综合浓度变化 量差值来表示再悬浮对湿地净化效果的影响, 6 次水质监测 (图 9) 显示, 再悬浮使湿地 $0.3 \mathrm{~m}$ 水深 $\mathrm{SS}$ 、 $\mathrm{COD}_{\mathrm{Mn}} 、 \mathrm{TN} 、 \mathrm{TP}$ 去除均值分别减少了 $14.83 、 0.87 、 0.036$ 和 $0.037 \mathrm{mg} / \mathrm{L}$, 随着水深增加, 再悬浮的影响均有所减 弱, 从再悬浮浓度值来看, $0.3 \mathrm{~m}$ 水深 $\mathrm{SS}$ 再悬浮浓度分别高出 $0.4 \mathrm{~m}$ 和 $0.5 \mathrm{~m}$ 水深 $12.48 \%$ 和 $18.67 \%$; $\mathrm{COD}_{\mathrm{Mn}}$ 分别高出 $12.61 \%$ 和 $19.52 \%$; TN 分别高出 $248.12 \%$ 和 $341.94 \%$; TP 高出分别 $35.53 \%$ 和 $43.48 \% .0 .4 、 0.5 \mathrm{~m}$ 水深 $\mathrm{TN}$ 的综合浓度变化量均值高于静置浓度变化量,再悬浮影响下甚至存在提升 TN 去除效果的现象.

\section{3 讨论}

\section{1 风场与流场作用下沉积物的再悬浮特征}

根据盐龙湖挺水植物区沉积物的分布特征及相关研究中沉积物的分层表述 ${ }^{[22]}$, 可将研究区域沉积物分 为氧化层、污染层、污染过渡层及健康层, 氧化层溶解氧充足, 在微生物的作用下形成团聚体结构, 增加了此 交界面的透水透气能力 ${ }^{[23]}$, 促进了氮的迁移转化, $\mathrm{TN}$ 含量较低, 颗粒态磷的直接沉降及表层氧化环境为磷 的固定提供了更多的吸附位点, TP 逐渐积累, 污染层长期的厌氧环境影响了对污染物的降解能力, 不断的 积累使得 TN 含量升高, 深度增加使得还原性变强, 造成磷的解吸和迁移 ${ }^{[24]}$, 污染过渡层是污染层向健康层 的过渡区域, 使该区域内营养物质含量又呈现下降趋势, 健康层几乎未受到污染, 其理化性质基本稳定. 这 种分层特征使得若引起氧化层的再悬浮, 会导致污染层裸露, 而污染层底泥营养物质含量相较于氧化层更 高, 增加了其释放程度 ${ }^{[22]}$. 

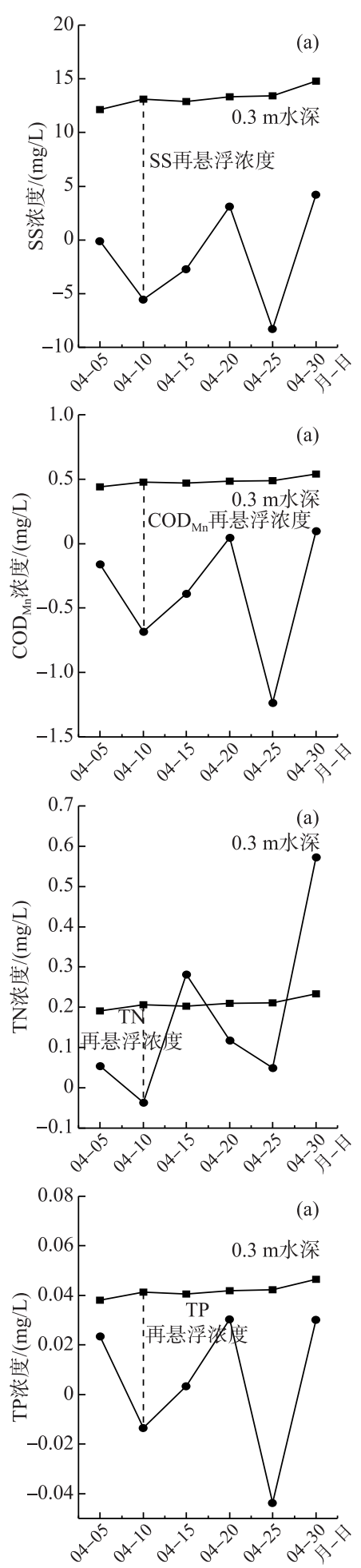

-—静置浓度变化量 一- 综合浓度变化量
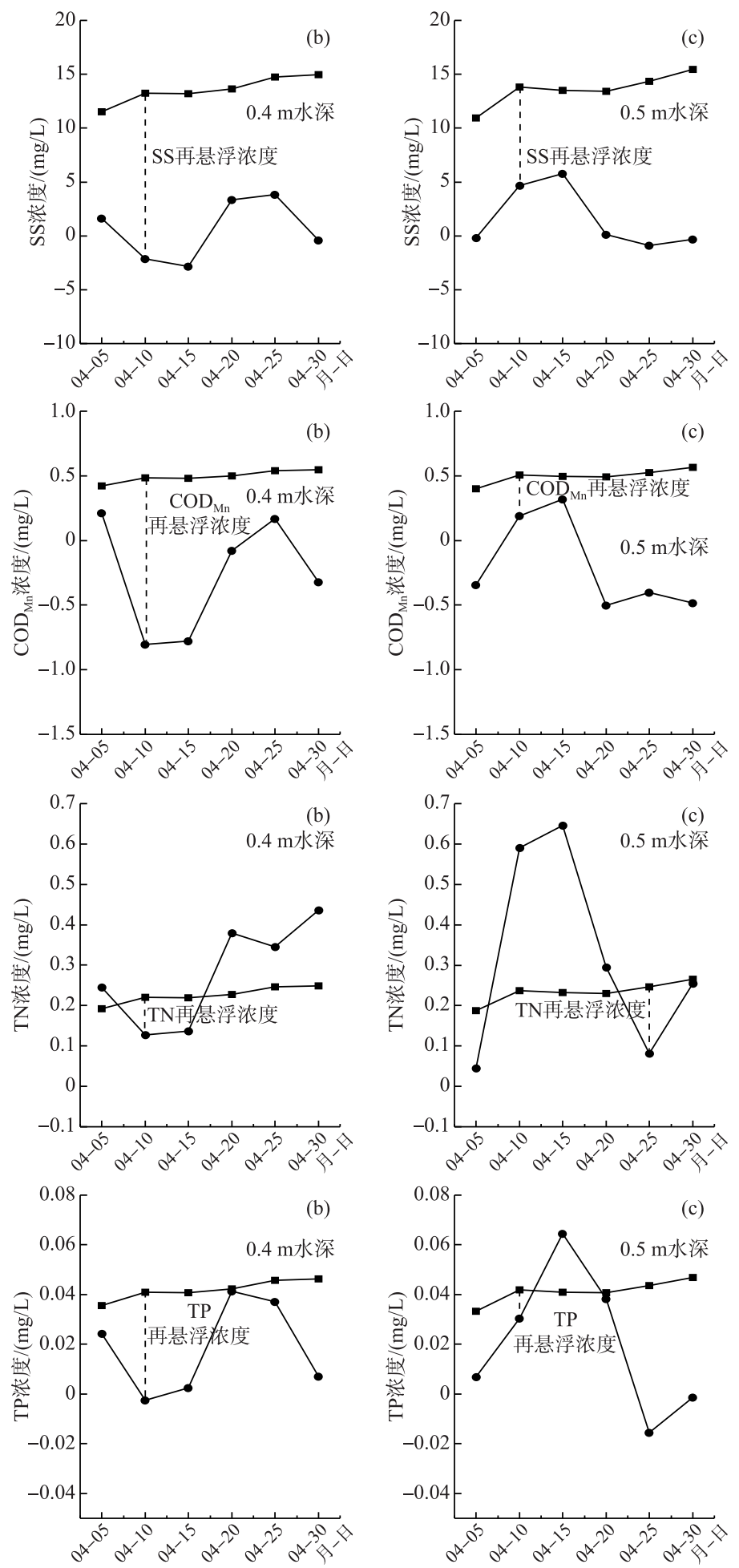

图 $90.3 \mathrm{~m}(\mathrm{a}) 、 0.4 \mathrm{~m}(\mathrm{~b}) 、 0.5 \mathrm{~m}(\mathrm{c})$ 水深 $\mathrm{SS} 、 \mathrm{COD}_{\mathrm{Mn}} 、 \mathrm{TN}$ 、TP 再悬浮浓度

Fig.9 SS, COD ${ }_{\mathrm{Mn}}, \mathrm{TN}$, TP resuspension under $0.3 \mathrm{~m}(\mathrm{a}), 0.4 \mathrm{~m}(\mathrm{~b}), 0.5 \mathrm{~m}(\mathrm{c})$ water depths 
通过计算沉积物再悬浮起动流速及临界切应力, 发现湿地现状内部流动并不足以引起沉积物的再悬 浮, 这与许多相关研究类似, 流场并不是引起沉积物再悬浮的主要因素, 风场驱动下形成的风生波及风生环 流现象是浅水沉积物再悬浮的主要动力 ${ }^{[11,25]}$.

萌发期与收割期风场和 SS 再悬浮浓度之间均表现为显著性相关 $(P<0.05)$, 萌发期为了满足植物幼苗 的生长需要; 收割期由于受季节、温度影响, 两个阶段湿地往往需要降低运行的水力负荷, 这在一定程度上 增加了风场的影响程度. 全年萌发期平均风速最大, 达到 $3.73 \mathrm{~m} / \mathrm{s}, \mathrm{SS}$ 日均再悬浮浓度为 $18.98 \mathrm{mg} / \mathrm{L}$, 也为 全年最大值; 收割期温度降低也使得分子布朗运动减弱, 悬浮颗粒之间碰撞几率降低, 悬浮物沉降性能下 降 ${ }^{[26]}$, 整个阶段 SS 日均再悬浮浓度达到 $15.32 \mathrm{mg} / \mathrm{L}$; 生长期与成熟期植物的风遮挡作用使得 SS 再悬浮浓 度减小, 与萌发期相比, SS 日均再悬浮浓度分别下降了 $31.02 \%$ 和 $37.22 \%$ ( 图 10), 与相关研究相比 ${ }^{[27]}$, 盐龙 湖植物的风遮挡作用对 SS 再悬浮量的削减作用较差, 分析一方面是由于研究区域内植物密度较大, 植物根 茎生长对土壤的挤压造成土壤表面凹凸不平, 土壤间形成的团聚体疏松多孔且相互粘结作用较弱, 同时生 长期与成熟期流速略有增大, 风场作用下形成波或者环流通过能量传递增加了床面沉积物的再悬浮; 另一 方面可能由于生长期与成熟期温度较为适宜, 再悬浮量易受底栖动物及水生生物的丰度和活性影响.

\section{2 营养物质再悬浮量估算}

2016 年 3 月 -2017 年 2 月监测结果显示萌发期、生长期、成熟期和收割期再悬浮浓度比值为 $1: 0.69$ : $0.63: 0.81$, 从整年的时间尺度来看, 可认为不同年份不同植物生长阶段再悬浮浓度的变化趋势近似一致, 以 上述 2018 年 4 月萌发期 6 次水质分析 SS 再悬浮浓度及不同时期再悬浮浓度的比值关系, 推算得到此时全 年不同时期再悬浮浓度均值分别为 $13.29 、 9.17 、 8.37$ 和 $10.76 \mathrm{mg} / \mathrm{L}$. 进水水质营养物质相对稳定, 根据 SS 与 颗粒态 $\mathrm{COD}_{\mathrm{Mn}}$ 、TPN、TPP 的关系均值及溶解态 $\mathrm{COD}_{\mathrm{Mn}}$ 与 $\mathrm{COD}_{\mathrm{Mn}}$ 、TDN 与 TN、TDP 与 TP 的关系, 按照湿地进 水量估算全年不同时期再悬浮过程中单位面积 $\mathrm{SS} 、 \mathrm{COD}_{\mathrm{Mn}} 、 \mathrm{TN} 、 \mathrm{TP}$ 的再悬浮量 (图 11). 结果显示全年 $\mathrm{SS}$ 、 $\mathrm{COD}_{\mathrm{Mn}} 、 \mathrm{TN} 、 \mathrm{TP}$ 再悬浮量分别为 $2.80 、 0.47 、 0.15$ 和 $0.011 \mathrm{~kg} / \mathrm{m}^{2}$, 其中萌发期 $\mathrm{SS} 、 \mathrm{COD}_{\mathrm{Mn}} 、 \mathrm{TN} 、 \mathrm{TP}$ 再悬浮量分 别达到9.96、1.66、0.55 和 $0.038 \mathrm{~g} /\left(\mathrm{m}^{2} \cdot \mathrm{d}\right)$, 为全年最大值; 成熟期受植物特征及风速大小影响, 营养物质再 悬浮量为全年最小, 与萌发期相比减少 $30 \%$ 以上. 周阳等 ${ }^{[13]}$ 在太湖植被区研究中也发现植被的作用可明显 控制水体悬浮物浓度, 当风速由 $2.8 \mathrm{~m} / \mathrm{s}$ 升至 $5.8 \mathrm{~m} / \mathrm{s}$ 时, 无植被带悬浮物浓度上升了 $119 \mathrm{mg} / \mathrm{L}$, 而植被覆盖 区仅上升了 $19 \mathrm{mg} / \mathrm{L}$. 但在风场作用下, 盐龙湖挺水植物区净化效果与理论条件下的静置浓度变化量相比明 显偏小, 湿地内部存在比较明显的再悬浮现象, 相关研究中也得到了类似的结论 ${ }^{[13,28]}$, 植被可以一定程度减 小风场作用下的再悬浮, 但植被种植区由于水生植物的调落分解, 表层营养物质累积量较高且更易释放, 使 得再悬浮过程中营养物质的释放量急剧增加.

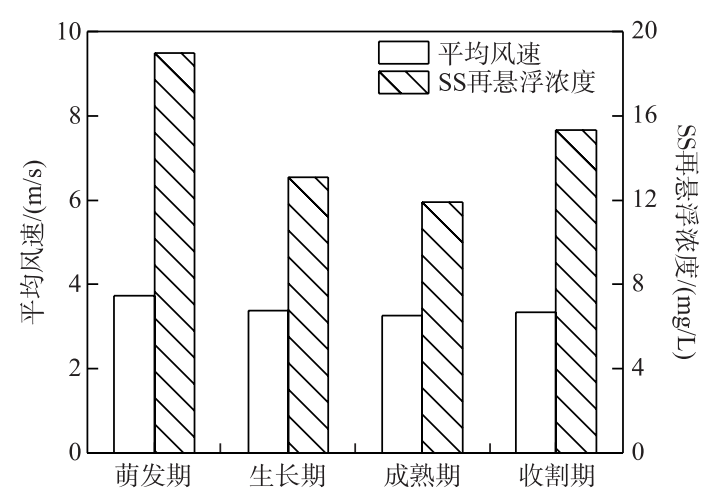

图 10 全年不同时期风速与 SS 日均再悬浮浓度分析

Fig.10 Analysis of SS resuspension concentration and wind speed in different periods of the year

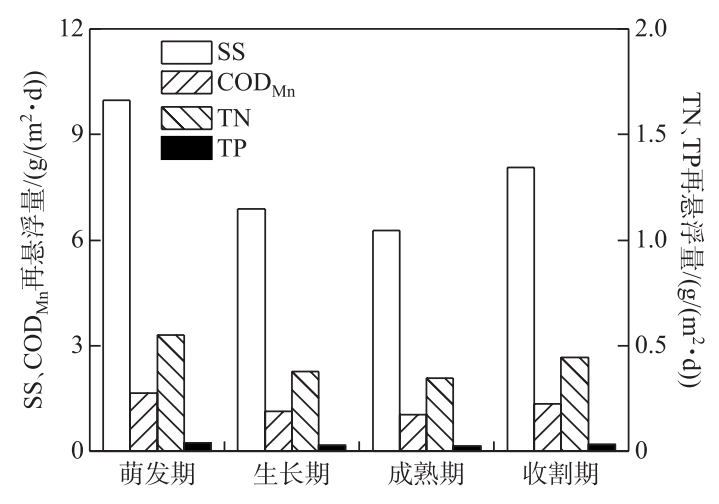

图 11 全年不同时期营养物质再悬浮量估算

Fig.11 Estimation of nutrient resuspension in different periods of the year 


\section{4 结论}

1) 以盐龙湖为代表类似的表面流人工湿地, 通常顶部 $0 \sim 10 \mathrm{~cm}$ 的沉积物营养盐浓度明显偏高, 但 $0 \sim 1$ $\mathrm{cm}$ 处水-土交界面营养物质含量通常小于 $1 \sim 4 \mathrm{~cm}$, 因此, 表层沉积物的再县浮可能会引发更多营养物质的 释放.

2) 研究范围内不同水深沉积物的理论起动流速介于 $18.54 \sim 22.62 \mathrm{~cm} / \mathrm{s}$ 之间, 湿地实际运行流速范围在 $0.22 \sim 1.62 \mathrm{~cm} / \mathrm{s}$ 之间,远小于理论值, 实际情况下仅流速的变化很难引起沉积物的再悬浮.

3 ) 萌发期和收割期风场与再悬浮浓度均呈现显著正相关, 当风速 $<2 \mathrm{~m} / \mathrm{s}$ 时再悬浮现象不明显, 风速 $>4$ $\mathrm{m} / \mathrm{s}$ 时再悬浮浓度显著增加.

4 ) 再悬浮对湿地净化效果的影响主要集中在萌发期与收割期, 同时营养物质的再悬浮量与湿地运行水 深有关, 全年 $\mathrm{SS} 、 \mathrm{COD}_{\mathrm{Mn}} 、 \mathrm{TN}$ 和 TP 再悬浮量分别达到 $2.8 、 0.47 、 0.15$ 和 $0.011 \mathrm{~kg} / \mathrm{m}^{2}$.

\section{5 参考文献}

[ 1 ] House WA, Denison FH, Smith JT et al. An investigation of the effects of water velocity on inorganic phosphorus influx to a sediment. Environmental Pollution, 1995, 89(3) : 263-271.

[ 2 ] Zhang L, Fan CX, Qin BQ et al. Phosphorus release and absorption of surficial sediments in Taihu Lake under simulative disturbing conditions. J Lake Sci, 2001, 13(1) : 35-42. DOI:10.18307/20010106. [张路, 范成新, 秦伯强等. 模拟扰 动条件下太湖表层沉积物磷行为的研究. 湖泊科学, 2001, 13(1):35-42.]

[ 3 ] Bailey MC, Hamilton DP. Wind induced sediment resuspension: A lake-wide model. Ecological Modelling, 1997, 99(2/ $3)$ : 217-228.

[ 4 ] Zhu G, Qin B, Gao G. Direct evidence of phosphorus outbreak release from sediment to overlying water in a large shallow lake caused by strong wind wave disturbance. Science Bulletin, 2005, 50(6) : 577-582.

[ 5 ] Wilson CG, Matisoff G, Whiting PJ et al. transport of fine sediment through a wetland using radionuclide tracers: Old Woman Creek, OH. Journal of Great Lakes Research, 2005, 31(1) : 56-67.

[ 6 ] Ganju NK, Schoellhamer DH, Bergamaschi BA. Suspended sediment fluxes in a tidal wetland: Measurement, controlling factors, and error analysis. Estuaries, 2005, 28(6) : 812-822.

[ 7 ] Marion L, Brient L. Wetland effects on water quality: input-output studies of suspended particulate matter, nitrogen( N) and phosphorus (P) in Grand-Lieu, a natural plain lake. Hydrobiologia, 1998, 374: 217-235.

[ 8 ] Gargallo S, Solimeno A, Martin M. Which are the most sensitive parameters for suspended solids modelling in free water surface constructed wetlands? Environmental Modelling \& Software, 2018, 102 : 115-119.

[ 9 ] Gargallo S, Martin M, Oliver N et al. Sedimentation and resuspension modelling in free water surface constructed wetlands. Ecological Engineering, 2017, 98: 318-329.

[10] Hu KM, Pang Y, Yu H et al. Study on the law of sediment release in Lake Taihu. Environmental Science \& Technology, $2011,34(12 \mathrm{H})$ : 7-12. [胡开明, 逢勇, 余辉等. 太湖底泥沉积物释放规律研究. 环境科学与技术, 2011, 34 $(12 \mathrm{H}): 7-12$.

[11] Qin BQ, Hu WP, Gao G et al. Dynamics of sediment resuspension and the conceptual schema of nutrient release in the large shallow Lake Taihu, China. Science Bulletin, 2003, 48(17) : 1822-1831. [秦伯强, 胡维平, 高光等. 太湖沉积物 悬浮的动力机制及内源释放的概念性模式. 科学通报, 2003, 48(17)：1822-1831.]

[12] Li YP, Wang JW, Jiang L et al. The driving force of sediment suspension on sediment-water interface in shallow lakes. $J$ Lake Sci, 2017, 29(1): 43-51. DOI: 10.18307/2017.0105. [李一平, 王建威, 姜龙等. 浅水湖泊动力作用下水-土界 面底泥起悬驱动力野外观测. 湖泊科学, 2017, 29(1): 43-51.]

[13] Zhou Y, Liu JE, Xu XG et al. Response of suspended solids and dissolved nutrients in littoral zone of Lake Taihu under wind-wave disturbances. J Lake Sci, 2018, 30(4) : 948-956. DOI: 10.18307/2018.0408. [周阳, 刘金娥, 许晓光等. 风 浪扰动下湖滨带悬浮物和营养盐响应特征. 湖泊科学, 2018, 30(4) : 948-956. ]

[14] Bao SD ed. Soil agrochemical analysis. Beijing: China Agricultural Press, 2013: 33-65. [鲍士旦. 土壤农化分析. 北京: 中国农业出版社, 2013: 33-65.]

[15] Dou GR. Incipient motion of coarse and fine sediment. Journal of Sediment Research, 1999, (6): 1-9. [窦国仁. 再论泥 
沙起动流速. 泥沙研究, 1999, (6) : 1-9.]

[16] Zhang HW. A unified formula for incipient velocity of sediment. Journal of Hydraulic Engineering, 2012, 43(12) : 1387 1396. [张红武. 泥沙起动流速的统一公式. 水力学报, 2012, 43(12)：1387-1396.]

[17] Fang CY. Flow resistance in compound channels with vegetation floodplains [Dissertation]. Chongqing: Chongqing Jiaotong University, 2010. [房春艳. 植被作用下复式河槽水流阻力实验研究 [ 学位论文]. 重庆: 重庆交通大 学, 2010.]

[18] Ji ZG ed. Hydrodynamics and water quality. Beijing: China Ocean Press, 2012: 62-63. [季振刚. 水动力学和水质. 北 京: 海洋出版社, 2012: 62-63.]

[19] Dou M, Jia RP. Optimization of water quality improvement program for Longfeng Wetland considering the purification of aquatic plants. Acta Scientiae Circumstantiae, 2018, 38(6) : 2418-2426. [窦明, 贾瑞鹏. 基于环境自净能力的龙凤湿 地水质改善优化调控模型. 环境科学学报, 2018, 38(6): 2418-2426.]

[20] Li L. Studies on the distribution of organic carbon, nitrogen, phosphorous and their correlation in Chaohu wetland sediments [Dissertation]. Wuhu: Anhui Normal University, 2010. [李雷. 巢湖湿地沉积物中有机碳、氮、磷分布特征及其 相关性研究 [ 学位论文]. 芜湖: 安徽师范大学, 2010.]

[21] Pang Y, Yan RR, Yu ZB et al. Suspension-sedimentation of sediment and release amount of internal load in Lake Taihu affected by wind. Environmental Science, 2008, 29(9) : 2456-2464. [ 逢勇, 颜润润, 余钟波等. 风浪作用下的底泥悬 浮沉降及内源释放量研究. 环境科学, 2008, 29(9) : 2456-2464.]

[22] Jiang X, Wang WW, Wang SH et al. Calculation of environmental dredging depth of heavy metal polluted sediments in Zhushan Bay of Taihu Lake. Environmental Science, 2012, 33(4): 1189-1197. [姜霞, 王雯雯, 王书航等. 笈山湾重金 属污染底泥环保疏浚深度的推算. 环境科学, 2012, 33(4): 1189-1197.]

[23] Mao R, Zhang XH, Meng HN. Effect of suaeda salsa on soil aggregate-associated organic carbon and nitrogen in tidal salt marshes in the Liaohe Delta, China. Wetlands, 2014, 34(1) : 189-195.

[24] Li XD, Sun TH, Li HB, Current researches and prospects of phosphorus removal in constructed wetland. Acta Ecologica Sinica, 2007, 27(3) : 1226-1232. [李晓东, 孙铁珩, 李海波等. 人工湿地除磷研究进展. 生态学报, 2007, 27(3): 1226-1232.]

[25] Zhu GW, Qin BQ, Zhang L et al. Wave effects on nutrient release of sediments from Lake Taihu by flume expeirments. $J$ Lake Sci, 2005, 17(1): 61-68. DOI:10.18307/2005.0110. [ 朱广伟, 秦伯强, 张路等. 太湖底泥悬浮中营养盐释放 的波浪水槽试验. 湖泊科学, 2005, 17 (1):61-68.]

[26] Chen X. Experimental study on deposition in static water of fine sediment of Yangtze River estuary [Dissertation]. Qingdao: Ocean University of China, 2013. [陈燨. 长江口细颗粒泥沙静水沉降试验研究 [学位论文]. 青岛: 中国海洋大 学, 2013.]

[27] Du GL. Study on sediment resuspension and the mechanism of nutrient release of Taihu Lake[Dissertation]. Nanjing: Nanjing Forestry University, 2013. [ 杜广龙. 太湖沉积物再悬浮及营养盐释放规律机制研究 [ 学位论文]. 南京: 南京林 业大学, 2013.]

[28 ] Shang LX, Ke F, Li WC et al. Laboratory research on the contaminants release during the anaerobic decomposition of highdensity cyanobacteria. J Lake Sci, 2013, 25(1) : 47-54. DOI: 10.18307/2013.0107. [尚丽霞, 柯凡, 李文朝等. 高密 度蓝藻厌氧分解过程与污染物释放实验研究. 湖泊科学, 2013, 25(1) : 47-54.] 